How to cite this article:

Lim, C. L., Ab Jalil, H., Maa'rof, A. M., \& Saad, W. Z. (2020). Self-regulated learning as a mediator in the relationship between peer learning and online learning satisfaction: A study of a private university in Malaysia. Malaysian Journal of Learning \& Instruction, 17(1), 51-75. https://doi.org/10.32890/mjli2020.17.1.3

\title{
SELF-REGULATED LEARNING AS A MEDIATOR IN THE RELATIONSHIP BETWEEN PEER LEARNING AND ONLINE LEARNING SATISFACTION: A STUDY OF A PRIVATE UNIVERSITY IN MALAYSIA
}

\section{${ }^{1}$ Chee Leong Lim, ${ }^{2}$ Habibah Ab Jalil, ${ }^{3}$ Aini Marina Ma'rof \& ${ }^{4}$ Wan Zuhainis Saad ${ }^{1}$ e-Learning Academy, Taylor's University, Malaysia ${ }^{1-4}$ Faculty of Educational Studies, Universiti Putra Malaysia Corresponding author: cheeleong.lim@taylors.edu.my}

Received: 13/9/2019 Revised: 22/11/2019 Accepted: 20/12/2019 Published: 31/1/2020

\section{ABSTRACT}

Purpose - Students' ability to self-regulate their learning and to learn effectively with peers are indicators of success in the era of the $4^{\text {th }}$ Industrial Revolution. This study investigated whether peer learning helps to influence online learning satisfaction in the presence of selfregulated learning (SRL) as a mediating variable.

Methodology - The study adopted a correlational research design to examine the possibility of relationships between these variables. The sample was selected based on proportional stratified sampling method. Of the 409 respondents, only 347 were valid for data analysis, forming a usable case of $84.84 \%$. The instrument used was an online questionnaire adapted from pre-existing reliable multi-item instruments. Structural Equation Model (SEM) analysis was used to examine the relationship between the constructs in the hypothesised model, while Bootstrapping test was applied to examine the mediation effects of SRL. 
Findings - From the direct effect of the SEM analysis, students' ability to learn with peers was found to have significantly influenced their SRL strategies, while SRL strategies were found to have a positive and statistically significant effect on online learning satisfaction. Moreover, the findings from the Bootstrapping test concurred that the influence of peer learning on online learning satisfaction was fully mediated by SRL.

Significance - By understanding the mediator roles played by SRL, this study hopes to provide insights for universities and course instructors to make pedagogically informed design decisions by integrating appropriate SRL strategies in the development of blended learning courses.

Keywords: Self-regulated learning, peer learning, online learning satisfaction, blended learning, mediating effect.

\section{INTRODUCTION}

In the past decade, both learners and educators in higher learning institutions have regarded blended learning as an effective pedagogy for improving learning outcomes. From the Teaching with Technology survey conducted by Campus Technology in 2016, 71\% of faculties worldwide reported that they were teaching in a highly blended learning environment (Kelly \& Schaffhauser, 2016). According to O'Connell (2016), blended learning has gained traction because of the growing awareness that the traditional lecture model has primarily been proven to be less effective. Compared to traditional teaching, blended learning has the potential to enrich, engage and enhance students' learning experiences and further improve the attainment of course learning outcomes.

The popularity of blended learning has largely resulted from many thought leaders who have played an active and strategic role in accelerating blended learning adoption in higher education. Blended learning courses have grown as students became more adept at navigating Virtual Learning Environments (VLEs) and learning how to engage meaningfully with online content. Won and Han (2016) posit that the flexibility and accessibility of blended learning empower students to integrate academic pursuits into their 
schedules better. With Learning Management Systems (LMS), educators are now empowered to create a more collaborative online learning environment and provide an adaptive learning experience for students by adopting evolving digital technologies.

As we embark on the Fourth Industrial Revolution, it is clear that innovations in learning technologies enable graduates to acquire skills and attributes that meet industry and society requirements. Therefore, educators are urged to efficiently and comprehensively deploy these technologies in their delivery, and equip students with Self-Regulated Learning (SRL) strategies and the ability to work effectively with peers, thus, helping them to become lifelong learners.

\section{LITERATURE REVIEW}

\section{Online Learning Satisfaction}

Satisfaction is worthy of investigation because it is critical to the motivations and aspirations of students in higher education online programs (Holder, 2007; McFarland \& Hamilton 2005). Learning satisfaction refers to learners' subjective perceptions about their learning experience and how well the learning environment supports their academic success (Lo, 2010). It is the attitude, perception and expectation of learners toward online learning environments $(\mathrm{Wu}$, Tennyson, \& Hsia, 2010). Satisfaction has also been defined as the relationship between learners' expectation and actual gains (Rashidi \& Moghadam, 2014). In this study, satisfaction is defined as a shortterm attitude resulting from a subjective evaluation of students' educational experience and outcomes in blended learning courses.

As satisfaction is a vital component of the effectiveness of an online course, students' online learning satisfaction has been established as one of the five pillars to be considered when determining quality in online education (Lorenzo \& Moore, 2002). Learning satisfaction is also a good predictor of retention in online programs (Lorenzo, 2012); it affects students' determination and inspiration to finish an online course and hence leads to lower drop-out rates (Zhu, 2012). Thus, studying online learning satisfaction helps universities to better retain students while recruiting more new students. It also enables 
universities to develop a strategic plan to improve the satisfaction of online learners (Noel-Levitz, Inc., 2011).

\section{Self-Regulated Learning}

Self-regulated learning (SRL) is one of the most important learning strategies in the context of blended learning. It highlights the dynamic personality of a learner's interactions as well as constructs self-regulated behaviour in learning tasks (Martin, 2004). SRL is defined as learners' systematic efforts to manage their learning process in order to attain personal goals (Zimmerman and Schunk, 2011). In Zimmerman and Schunk's terms, self-regulated learning is a process in which learners resort to self-regulatory skills such as self-assessing, self-directing, controlling and adjusting in order to obtain knowledge. It is also a process where students acquire self-regulation skills by actively monitoring their own learning to improve their academic performance. In this study, Zimmerman's (1989) perspective of SRL, which draws from social cognitive theory, was chosen as the theoretical foundation because it is aligned well with the characteristics of blended learning environments. In Zimmerman's Three-Phase Model, SRL is a cyclical process where the person (self), behaviour, and environment are factors which interact with each other. When one of these three factors changes, the change will be monitored and this leads to changes in the other factors (Schunk et al., 2008).

\section{Peer Learning}

Throughout the years, many researchers have studied the concept of peer learning and derived different definitions in the context of teaching and learning. One of the earliest scholars to study about it was Topping (1996), who defined peer learning as the process which occurs when people of similar backgrounds, and are not tutors, work together and teach each other to understand certain educational topics. Boud, Sampson, Cohen, \& Gaynor (2001) offered a simpler definition of peer learning as simply the idea of different students learning from each other formally and informally. Generally, peer learning refers to the ability of peers to work with one another and assist each other to learn.

Peer learning has been found to be useful to enhance students' learning. For example, in a recent study, Hussain \& Al Saadi 
(2019) found that the use of authentic assessments in a peer learning environment enabled students to collaborate and become motivated. When a peer learning strategy is implemented correctly, it improves students' learning satisfaction. This strategy is one of the most effective methods to boost students' confidence and make them believe in their skills (Keppell, Suddaby, \& Hard, 2011). It has also grown widely as an effective educational tool, especially in the context of health sciences in higher education (Williams et al., 2012; Brannagan et al., 2013).

\section{Hypothesised Relationship between Peer Learning and Self- Regulated Learning (SRL)}

In a peer learning setting, students engage in cyclical interactions that stimulate the practice and use of self-regulatory behaviours in all phases of SRL (Zimmerman, 2008). Also, as feedback is often bidirectional, when students often provide feedback to their peers and help other students correct their own misconceptions, this behaviour will contribute to the increase of SRL skills (Boekaerts \& Cascallar, 2006). Zimmerman (1989) stated that when students help each other practice, it thereby internalizes their task strategies, thus helping them to increase their SRL skill levels. Similarly, helpseeking and help-giving behaviours among peers often foster the acquisition of SRL.

Students acquire SRL skills during the peer learning process because several aspects of peer learning provide mechanisms for them to acquire SRL skills. For instance, peer learning provides more opportunities for peer-to-peer interactions as compared to teacherstudent interactions. Asking for help from peers often encourages students to practice self-regulatory skills such as self-reflection. Another aspect is related to shared responsibility. The general belief is that during the peer learning process, students distribute and share thinking responsibilities. Shared responsibility for thinking is an active activity and requires students to regulate their learning by using learning strategies such as help-seeking (Zimmerman, 1989) and attempting to understand the thoughts of others during task performance. Based on these assertions, the current study hypothesized the following:

H1. Peer learning influences students' self-regulated learning (SRL) strategies in blended learning courses. 


\section{Hypothesised Relationship between Self-Regulated Learning (SRL) and Online Learning Satisfaction}

In blended learning environments, learners assume more responsibility, flexibility and autonomy; therefore, self-regulation becomes a critical success factor in online learning (Barnard, Lan, To, Paton, \& Lai, 2009). When learners acquire better skills in SRL, they are more likely to demonstrate higher course satisfaction and are subsequently more successful in their learning (Barnard, Paton, \& Lan, 2010; Cho \& Shen, 2013). Similarly, researchers have also reported that less self-regulated learners may abuse the flexibility given in the blended learning environment; therefore, they are less satisfied in their learning, which leads less success in learning (Lee, Shen \& Tsai, 2008).

SRL is a vital element for developing students' successful learning experiences in the delivery of online instruction for blended learning courses (Broadbent \& Poon, 2015). Generally, students will have a positive perception of blended courses when they are able to engage in more online self-regulatory learning behaviours. This is because during online instruction, students assume greater responsibility and autonomy for their learning. When they acquire the skills to regulate different learning strategies in their learning process, they will gain greater satisfaction in learning, and hence have higher chances of being successful in blended learning courses. These claims find support in a study by Rowe \& Rafferty (2013), which has revealed that learners with a high inclination for self-regulated learning may find more satisfaction in blended courses. Therefore, the current study hypothesized the following:

$\mathrm{H}_{2}$ : Students' self-regulated learning (SRL) strategies influence online learning satisfaction in blended learning courses.

\section{Mediating Role of Self-Regulated Learning (SRL)}

As SRL abilities are crucial for mediating success in different learning environments (Lehmann, Hähnlein \& Ifenthaler, 2014), it has become one of the most important areas of research within educational studies. Many researchers have studied SRL within a comprehensive and holistic approach in learning (Panadero, Jonsson, \& Botella, 2017). Literature has shown that SRL serves as a mediator in many different contexts related to learning outcomes, 
including learning satisfaction. Barnard et al.'s (2010) research on the mediating role of SRL found that online SRL behaviours do mediate the relationship between perceptions of online courses and academic achievement. Based on Structural Equation Modelling (SEM) results, it was concluded that the positive relationship between perceptions of online course communication and academic achievement is mainly due to the increase of online self-regulatory learning behaviours.

Similarly, according to Pintrich's SRL model (2000), selfregulatory activities also serve as mediators between individuals, contextual characteristics and their actual academic achievement. This was empirically supported by Taura, Abdullah, Roslan and Omar (2014) who used SEM to examine whether self-regulation mediated the relationships between self-efficacy, task value, and active procrastination. Recently, Morosanova and Fomina (2017) have found that conscious self-regulation acts as a mediator in the relationship between the test anxiety of students and their academic performance. Based on these studies, the current study hypothesized the following:

$H_{3}$. SRL mediates the effects of peer learning on online learning satisfaction in blended learning courses

The hypothesized model of the current research is shown in Figure 1.

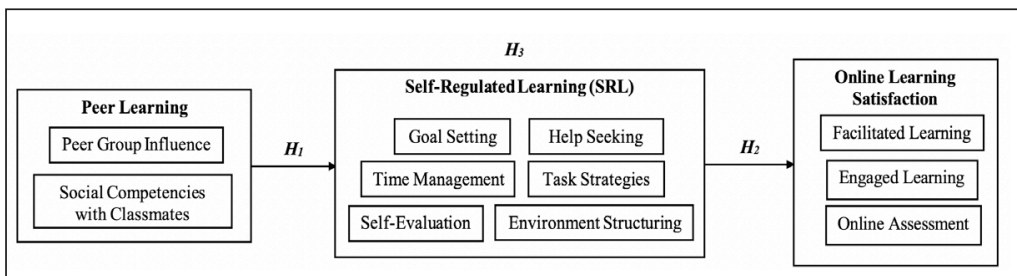

Figure 1. Hypothesized Model of the Current Research.

\section{METHODOLOGY}

\section{Research Design}

The aim of this study was to determine the causal relationships among students' self-regulated learning (SRL) abilities, peer learning, and online learning satisfaction in a blended learning environment. 
Therefore, it adopted a correlational research design to investigate the possibility of relationships between these variables without any attempt to influence or manipulate them. To establish a Structural Equation Model (SEM), peer learning was used as an exogenous variable, while students' SRL and online learning satisfaction were endogenous variables. Path analysis through AMOS software examined the causal relationship between exogenous and endogenous variables.

\section{Location and Population of the Study}

This study was conducted in a private university located in the Klang Valley, Malaysia. The target population comprised undergraduate students $(\mathrm{N}=7515)$ taking credit-bearing courses offered in blended learning mode at this university during the March 2019 semester.

\section{Sample Size}

The minimum sample size for this study was guided by Cochran's equation and formula (1977), as shown below

$$
\mathrm{n}_{\mathrm{o}}=\frac{Z^{2} \mathrm{p} \text { l }}{\mathrm{s}^{2}}
$$

where $\mathrm{n}_{\mathrm{o}}=$ calculated sample size; $\mathrm{Z}=\mathrm{z}$ score of confidence level; $\mathrm{p}^{*} \mathrm{q}=$ variance of hypothesized proportion; $\mathrm{e}=$ desired margin of error

$$
\begin{aligned}
& \mathrm{n}_{\mathrm{o}}=\frac{1.96^{2} \times 0 \mathrm{3} \times 0.5}{0.05^{2}}=384.16 \\
& \mathbf{n}=\frac{\pi_{1}}{1-\frac{n_{11}}{\mathrm{n}}}
\end{aligned}
$$

where $n=$ corrected estimation of sample size; $N=$ population size

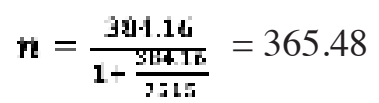

Therefore, Cochran's formula suggested 366 as the minimum sample size for this study.

\section{Sampling Procedure}

To reduce possible bias in competency levels among learners in a particular academic discipline, as well as to ensure the sample 
size taken from each faculty is proportionate to its population size when viewed against the entire university, the proportional stratified sampling method was used. This was to ensure each subgroup of undergraduates from different faculties within the university had the same sampling fraction and presented results in the same proportion as they were in the population.

The target population of the study was divided into 4 subgroups according to faculty, as presented in Table 1. In the second stage, each faculty was divided according to the academic disciplines under the different schools. The minimum sample size for faculty was determined proportionately based on the recommended sample size $(n=366)$.

Table 1

Summary of the Proportionate Sample Size

\begin{tabular}{llll}
\hline Faculty & $\begin{array}{l}\text { No. of } \\
\text { undergraduates }\end{array}$ & $\begin{array}{l}\% \text { of } \\
\text { sample }\end{array}$ & $\begin{array}{l}\text { Sample } \\
\text { size }\end{array}$ \\
\hline
\end{tabular}

\section{Faculty of Business \& Law (FBL)}

\begin{tabular}{llcc} 
Marketing & 847 & 11.3 & 41 \\
Finance \& Economics & 805 & 10.7 & 39 \\
Law & 282 & 3.8 & 14 \\
Sub-Total & $\mathbf{1 , 9 3 4}$ & $\mathbf{2 5 . 7}$ & $\mathbf{9 4}$ \\
\hline
\end{tabular}

Faculty of Social Sciences \& Leisure Management (FSLM)

Communication

Education

Liberal Arts and Sciences

Culinary Arts and Food Studies

Hospitality, Tourism and Events

Sub-Total 


\begin{tabular}{llll}
\hline Faculty & $\begin{array}{l}\text { No. of } \\
\text { undergraduates }\end{array}$ & $\begin{array}{l}\text { \% of } \\
\text { sample }\end{array}$ & $\begin{array}{l}\text { Sample } \\
\text { size }\end{array}$ \\
\hline $\begin{array}{l}\text { Faculty of Health \& Medical } \\
\text { Sciences (FHMS) }\end{array}$ & 163 & & \\
$\begin{array}{l}\text { Pharmacy } \\
\text { Biosciences }\end{array}$ & 383 & 2.2 & 8 \\
$\begin{array}{l}\text { Medicine } \\
\text { Sub-Total }\end{array}$ & 270 & 5.1 & 19 \\
\hline $\begin{array}{l}\text { Faculty of Innovation \& } \\
\text { Technology (FIT) }\end{array}$ & $\mathbf{8 1 6}$ & 3.6 & 13 \\
$\begin{array}{l}\text { Design } \\
\text { Engineering }\end{array}$ & $\mathbf{1 0 . 9}$ & $\mathbf{4 0}$ \\
$\begin{array}{l}\text { Architecture, Building \& } \\
\text { Design }\end{array}$ & 995 & 5.7 & 21 \\
$\begin{array}{l}\text { Computing and Information } \\
\text { Technology }\end{array}$ & 439 & $\mathbf{1 0 0}$ & $\mathbf{3 6 6}$ \\
$\begin{array}{l}\text { Sub-Total } \\
\text { Overall Total }\end{array}$ & $\mathbf{2 , 3 3 6}$ & 13.2 & 48 \\
\hline & 470 & 5.8 & 21 \\
\hline
\end{tabular}

\section{Data Collection Procedure}

An online self-report questionnaire was created and administered using SurveyMonkey.com. The survey links were then distributed through the university's official Learning Management System(LMS) in the March 2019 semester. To reduce possible bias in competency levels among learners in a particular academic discipline, a total of 45 blended courses across 15 different academic disciplines were selected, including Engineering, Business, Biosciences, Medicine and many more. The survey link was posted in the announcement section of each blended course 4 weeks before the end of the semester. A recruitment message was sent to instructors via email at the middle of the semester, and respondents did not have any direct contact with the researcher. 
All the blended courses selected for this study met the following characteristics: (a) students were undergraduates, (b) the courses were the top 3 most active blended learning courses in their respective schools for the March 2019 semester, as measured by student participation rates, (c) each course had various learning objects or activities for each blended learning component as defined by the university, which included Resource, Activity and Assessment, and (d) the instructors used the university's LMS portal as their platform for blended learning delivery.

\section{Demographic Profile of the Respondents}

The intended population of this study was the students who were taking credit-bearing courses offered in blended learning mode at this university. Of the 409 respondents, only 347 were valid for data analysis. 62 respondents were excluded due to incomplete responses with missing values, including invalid student identification number, and inappropriateness of action in giving responses, such as spending less than a minute to complete the online survey or having a monotonous pattern in answering the questionnaire. Consequently, data from 347 respondents were analysed, forming a usable case of $84.84 \%$. The demographic profile of the respondents is shown in Table 2.

Table 2

Demographic Profile of the Respondents

\begin{tabular}{lll}
\hline Demographic Variables & Frequency $(\mathbf{n})$ & Percentage $(\boldsymbol{\%})$ \\
\hline Gender & & \\
Male & 132 & 38.0 \\
Female & 215 & 62.0 \\
Faculty & & \\
Business \& Law & 103 & 29.7 \\
Social Sciences \& Leisure & 103 & 29.7 \\
Management & & \\
& & 12.2 \\
Health \& Medical Sciences & 42 & 28.4 \\
Innovation \& Technology & 99 & \\
\hline Total & & $\mathbf{1 0}$ \\
\hline
\end{tabular}




\section{Measurement and Instrumentation}

The questionnaire employed in this study was adapted from preexisting multi-item instruments derived according to the literature review and research objectives. The first instrument, for gathering respondents' demographic information, was developed by the researchers, while the remaining three instruments, namely (i) Online Learning Satisfaction, (ii) Self-Regulated Learning (SRL) Strategies and (iii) Peer-Learning Strategies, were adapted from several established instruments which are widely used and fairly tested for their reliability and validity. Permission was obtained from the respective authors to use and adapt these instruments for the purpose of this study.

(i) Online Learning Satisfaction: 18 items were adapted from the Sloan Model of Student Satisfaction in Asynchronous Learning Networks (ALN) developed by Dziuban, Hartman, Moskal, Brophy-Ellison, \& Shea (2007) and Dziuban et al. (2015).

(ii) Self-Regulated Learning: 27 items were adapted from the Online Self-Regulated Learning Questionnaire (OSLQ) established by Barnard et al. (2009).

(iii) Peer Learning: 14 items were adapted from Social Competency with Peers in Online Learning developed by Shen, Cho, Tsai and Marra (2013) and the Peer Group Influence Assessment Questionnaire (PGIAQ) developed by Uzezi and Deya (2017).

\section{DATA ANALYSIS AND RESULTS}

\section{Full Measurement Model}

Generating a full measurement model is crucial prior to generating a structural model. The main purposes of a measurement model include (i) test for model fit, and (ii) test for discriminant validity. Figure 2 presents the full measurement model after a series of modifications based on CFA. Based on the Goodness-Of-Fit (GOF) indices, the CFA reported a good fit between data and the suggested model with $\chi 2 / \mathrm{df}=1.697 ; \mathrm{CFI}=0.916 ; \mathrm{IFI}=0.917 ; \mathrm{TLI}=0.912$ and $\mathrm{RMSEA}$ $=0.045$. The results showed that the measurement model was fit forsubsequent structural model analysis. 


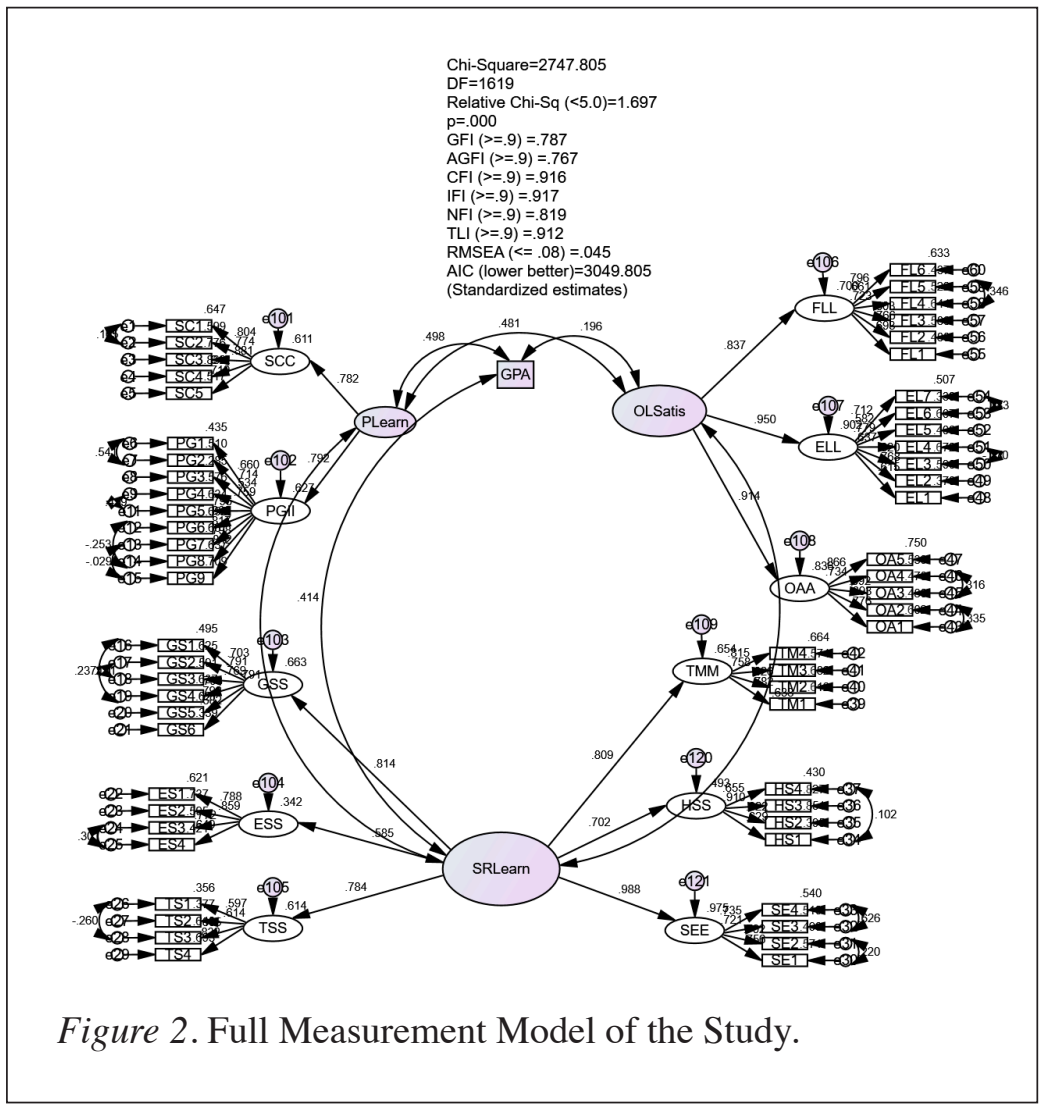

Table 3

Discriminant Validity of the Latent Constructs

\begin{tabular}{llllll}
\hline Constructs & CR & AVE & OLS & PLearning & SRL \\
\hline OLS & 0.929 & 0.813 & $\mathbf{0 . 9 0 2}$ & & \\
PLearning & 0.767 & 0.623 & 0.481 & $\mathbf{0 . 7 8 9}$ & \\
SRL & 0.907 & 0.625 & 0.640 & 0.789 & $\mathbf{0 . 7 9 0}$ \\
\hline
\end{tabular}

Note: The squared root of AVE of each construct presented on the diagonal and correlation coefficients are located on the correlational matrix.

As illustrated in Table 3, the results showed the squared root of AVE for each latent construct (numbers on diagonal of matrix) was larger 
than each of the correlation coefficient between constructs (numbers off-diagonal of matrix). Therefore, the results established good discriminant validity of the constructs.

\section{Structural Equation Modeling (SEM) Analysis}

The structural model was used to examine and describe the direct influence of peer learning and SRL strategies on respondents' learning satisfaction in blended learning courses. As shown in Figure 3, the results of assessing the structural model fits indicated that the data fitted the model with $\chi^{2} / \mathrm{df}=1.697$; CFI $=0.916$; IFI $=0.917$; TFI $=0.912$; and RMSEA $=0.045$. Therefore, based on the recommendation from Hair et al. (2010), it was concluded that the structural model fit the Goodness-of-fit indices, which was the indication of an acceptable fit between the hypothetical model and the data collected. Consequently, further analysis could be processed using the structural model.

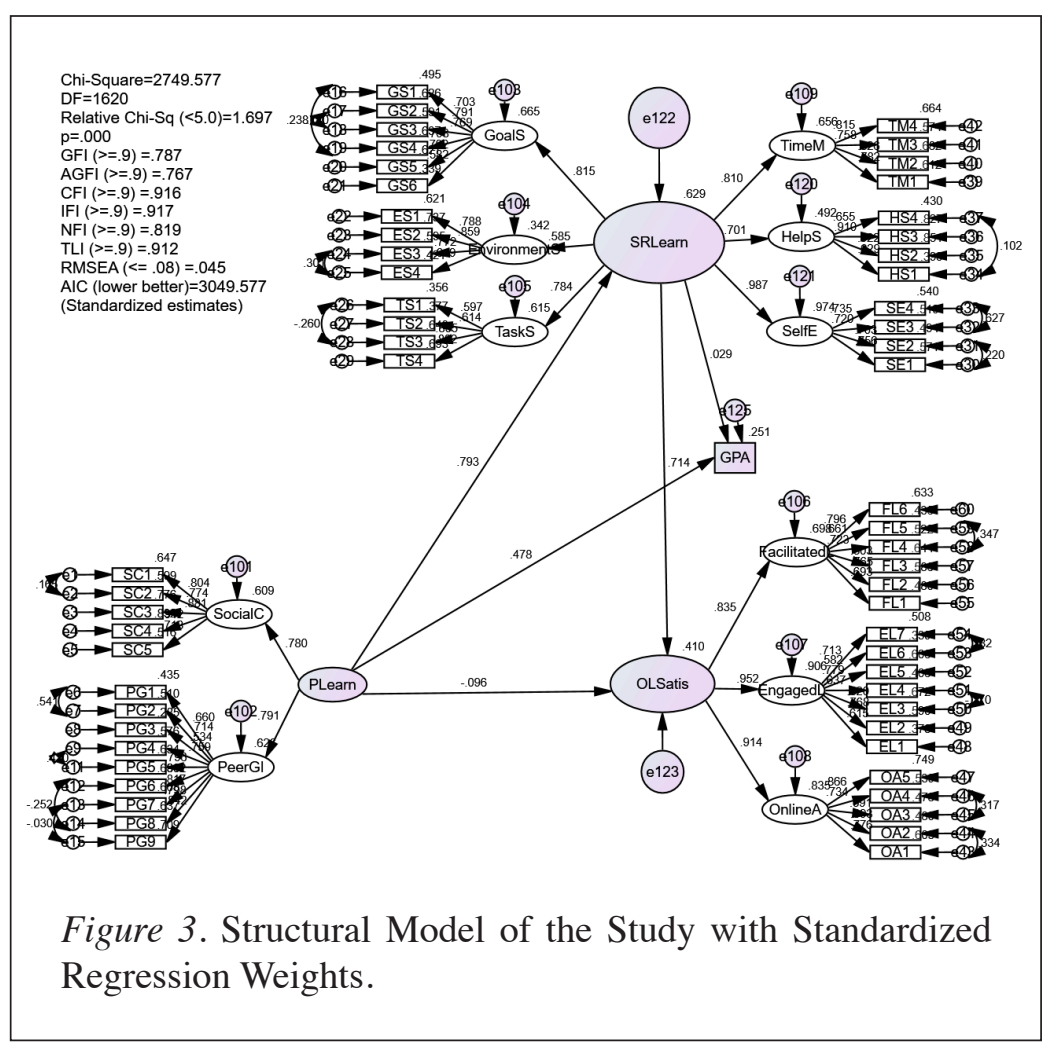




\section{The Hypothesized Direct Effect of Peer Learning on Self-Regulated Learning (SRL) Strategies}

The results in Table 4 indicate that peer learning had a positive and statistically significant effect on students' SRL strategies $(\beta=$ 0.793; C.R. $=6.991 ; p=0.000)$. Therefore, $\mathrm{H} 1$ was supported by the results of the structural model estimation, i.e., the ability to learn from and with peers influenced students' SRL strategies in blended learning courses. Furthermore, the standardized estimate of $\beta$ was 0.793 , indicating a positive relationship. This means that when peer learning went up by 1 standard deviation, self-regulated learning (SRL) strategies went up by 0.793 standard deviations.

Table 4

Regression Weights in the Hypothesized Direct Model on the Effect of Peer Learning on Self-Regulated Learning Strategies

\begin{tabular}{llllll}
\hline Hypothesized Relationship & B & S.E. & $\boldsymbol{\beta}$ & C.R. & $\boldsymbol{p}$ \\
\hline Peer Learning à SRL & 0.528 & 0.076 & 0.793 & 6.991 & 0.000 \\
& & & & & \\
\hline
\end{tabular}

Note: B (unstandardized regression weight); S.E. (standard error); $\beta$ (standardized regression weight); C.R. (critical ratio)

\section{The Hypothesized Direct Effect of the Predictors on Online Learning Satisfaction}

As illustrated in Table 5, the results indicated that students' selfregulated learning (SRL) strategies had a positive and statistically significant effect on online learning satisfaction $(\beta=0.714$; C.R. $=5.150 ; p=0.000)$. Based on the structural model, the null hypothesis was rejected. Therefore, $\mathrm{H} 2$ was supported by statistical evidence, i.e., self-regulated learning (SRL) strategies significantly influenced students' online learning satisfaction in blended learning courses. Moreover, the standardized estimate of $\beta$ was 0.714 , indicating a positive relationship, i.e., when self-regulated learning (SRL) strategies went up by 1 standard deviation, online learning satisfaction went up by 0.714 standard deviations. 
Table 5

Regression Weights in the Hypothesized Direct Model on Effect of Predictors on Online Learning Satisfaction

\begin{tabular}{llllll}
\hline Hypothesized Relationship & B & S.E. & $\boldsymbol{\beta}$ & C.R. & $\boldsymbol{p}$ \\
\hline SRL à OLS & 0.953 & 0.185 & 0.714 & 5.150 & 0.000 \\
\hline
\end{tabular}

Note: B (unstandardized regression weight); S.E. (standard error); $\beta$ (standardized regression weight); C.R. (critical ratio)

\section{Bootstrapping for Mediation Effects Test}

Bootstrapping test was applied to test the mediating effect of SRL using a resampling technique which involved resampling from one sample data (Hayes, 2009). Generally, the minimum number of resampling is 1000 times. However, this study selected 5000 bootstrap samples and a 95\% confidence interval for the bias-corrected option. Derivation of the mediation effect of SRL in this study was based on the percentile confidence interval. If it did not include zero, then it was concluded that the indirect impact was statistically significant at 0.05 level of significance with bias-corrected.

The bootstrapping results from the mediation test (see Table 6) showed that there was a significant relationship between Peer Learning and Online Learning Satisfaction (OLS) in the absence of Self-Regulated Learning (SRL), with the standardized total effect of 0.433 and the P-value of 0.000 . Thus, the total effect of Peer Learning as IV on Online Learning Satisfaction (OLS) as DV without the inclusion of Self-Regulated Learning (SRL) as M was statistically significant.

This relation became non-significant after the inclusion of SelfRegulated Learning (SRL) into the model, with the standardized total effect of -0.096 and a P-value of 0.403 . Thus, the direct effect of Peer Learning as IV on Online Learning Satisfaction (OLS) as DV with the inclusion of SRL as M was statistically non-significant. 
Table 6

Bootstrap Results of Mediation Effect of SRL on the Relationship between Peer Learning and Online Learning Satisfaction

\begin{tabular}{|c|c|c|c|c|c|c|}
\hline \multicolumn{3}{|l|}{ Model/ } & \multicolumn{2}{|c|}{$\underline{95 \% C I B C}$} & \multirow[b]{2}{*}{$\varkappa^{2}$} & \multirow[b]{2}{*}{ Mediation } \\
\hline Hypothesized Paths & Beta & $p$ & $L B$ & $\boldsymbol{U B}$ & & \\
\hline Direct Model & 0.433 & 0.000 & & & & \\
\hline \multicolumn{7}{|l|}{ Peer Learning $\rightarrow$ OLS } \\
\hline Mediation Model & -0.096 & 0.403 & & & & \\
\hline Peer Learning $\rightarrow$ OLS & 0.566 & 0.000 & 0.392 & 0.932 & 0.404 & Full Mediation \\
\hline \multicolumn{7}{|l|}{ Standardized Indirect } \\
\hline Effect (SIE) & & & & & & \\
\hline
\end{tabular}

Note: Indirect effect is significant if zero (0) falls outside the lower bound (LB) and upper bound (UB); 95\% CI BC: Bias Corrected at 95\% Confident Interval; LB= Lower Boundary; $\mathrm{UB}=$ Upper Boundary.

Besides, the results also revealed that Peer Learning had a significant indirect positive effect on Online Learning Satisfaction(OLS) through Self-Regulated Learning (SRL) with the standardized indirect effect of 0.566 and a P-value of 0.000 , with $\mathrm{LB}=0.392$ and $\mathrm{UB}=0.932$. Since the bias-corrected at $95 \%$ confidence interval did not include zero, the result indicated that Self-Regulated Learning mediated the relationship between Peer Learning on Online Learning Satisfaction at the 0.05 level of significance, and the degree of mediation was full. Thus, $\mathrm{H}_{3}$ was supported by bootstrapping analysis.

The standardized indirect (mediated) effect of Peer Learning on Online Learning Satisfaction was 0.566. This result indicated that when Peer Learning went up by 1 standard deviation, Online Learning Satisfaction went up by 0.566 standard deviations. This was in addition to any direct (unmediated) effect that Peer Learning might have on Online Learning Satisfaction.

Lastly, Preacher and Kelley (2011) suggested using Kappa Square $\left(\varkappa^{2}\right)$ value in the same manner as the coefficient of determination 
$\left(\mathrm{R}^{2}\right)$, where small, medium and large effect sizes are stated as 0.01 , 0.09 and 0.25 respectively. Therefore, it was concluded that the indirect effect of Peer Learning on Online Learning Satisfaction through Self-Regulated Learning was considerably large, with Kappa Square $\left(\varkappa^{2}\right)=0.404$.

\section{DISCUSSION, IMPLICATIONS AND CONCLUSION}

\section{Discussion of Findings}

This study found that peer learning affected online learning satisfaction only through self-regulation $(\beta=0.566)$. As shown in Figure 4, the direct effect of peer learning on online learning satisfaction became non-significant after including SRL as a mediator ( $\beta=-0.096)$. In other words, the mediational effect through SRL was full, as opposed to partial.

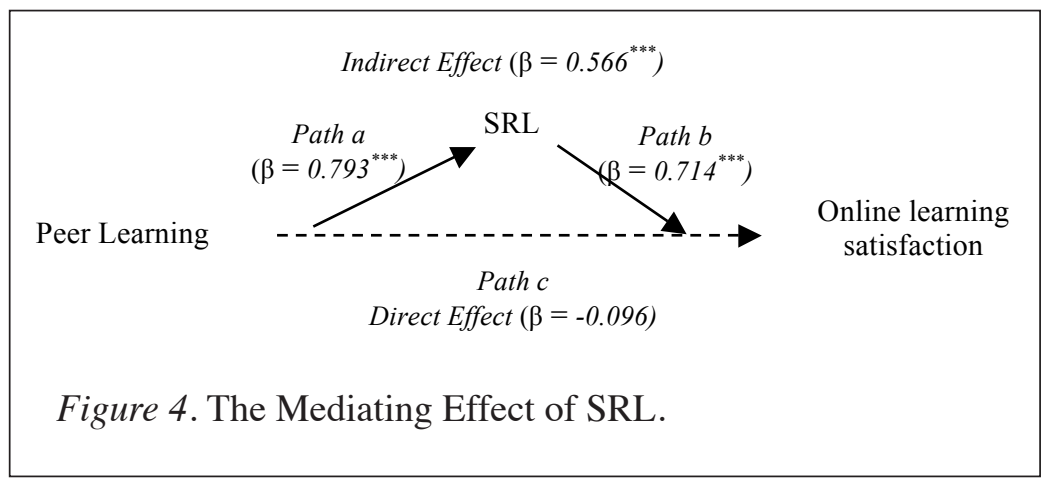

Note: $* \mathrm{p}<0.05 ; * * \mathrm{p}<0.01 ; * * * \mathrm{p}<0.001$. Dotted lines denote non-significant impact.

This result supported the assumption that improvement in student satisfaction after implementing peer learning intervention was due to improvements in students' SRL strategies. Therefore, it was concluded that the impact of peer learning on satisfaction was solely due to SRL strategies employed by the students. In other words, students who failed to learn effectively from and with peers would also find it difficult to self-regulate their behaviour, thus resulting in low satisfaction when studying online. 
Most of the past literature exploring the impact of SRL was usually focused on improvements in learning satisfaction (Li, 2019; Wong et al., 2019). The assumption made was that effective peer learning environments would stimulate students' self-regulation behaviours and subsequently influence them to employ a variety of SRL strategies, such as time management, effort management and environment structuring strategies (Puzziferro, 2008), as shown in Path a (Figure 4). This in turn would lead to increased learning satisfaction (Li, 2019; Rowe \& Rafferty, 2013), as shown in Path b. In addition, there were also studies that examined the direct relationship between peer learning and online learning satisfaction (Choi, 2016), as shown in Path c.

As explained in the previous sections, while past researchers have investigated the direct effect of peer learning on SRL strategies as well as the direct impact of SRL strategies on learning satisfaction, none or very few of these studies have tested the mediating role of SRL on the effect of peer learning and online learning satisfaction in their analyses. Hence, this study adds to the literature on both peer learning and online learning satisfaction by introducing SRL as the mediating variable that interacts with peer learning to influence satisfaction. Also, since the effectiveness of peer learning in improving students' online learning satisfaction was due to improvements in SRL, these findings reiterate the need for educators to provide the support and learning tools necessary to further develop and strengthen students' self-regulation in order to increase their learning satisfaction.

\section{THEORETICAL IMPLICATIONS}

The study contributes to the existing body of knowledge on blended learning in several ways. First, it proposes an integrated, coherent and actionable framework covering a variety of constructs, including SRL strategies, peer learning, online learning satisfaction and academic achievement in the context of blended learning. The conceptualization of such a model provides immense value towards improving our knowledge about the causal relationships among these variables and the moderator roles of gender and academic disciplines on the determinants of learning outcomes attainment. In addition, this study contributes to the literature on both peer learning 
and online learning satisfaction by introducing SRL as the mediating variable that interacts with peer learning to influence satisfaction. The finding that SRL serves as a full mediator in the relationship between peer learning and online learning satisfaction has also yielded a more comprehensive picture of SRL within the blended learning environment. Future research would benefit from exploring how the mediator effect of learner self-regulation could work together with a peer learning approach to further improve students' online learning satisfaction.

\section{Implications to Instructional Designers}

When designing courses for blended learning, instructional designers should incorporate instructional scaffolding to assist students in developing SRL skills. This could be done by intentionally breaking up a learning object into smaller manageable chunks, and then integrating different learning opportunities and assessments within each chunk that would encourage goal setting, planning and reflection, in order to foster students' positive self-regulation. Organizing eLearning content in a logical and progressive way through chunking is particularly important in the virtual learning environment. This is because learners are highly autonomous and are required to be independent in blended learning courses.

\section{Recommendations for Practice in Education}

Digital badges are another emerging tool used to support selfregulation in the virtual learning environment. It captures and communicates what students learn and what they can demonstrate. With learning today increasingly made to be ubiquitous, digital badges are being used to inform students about the completion of a learning milestone. Digital badges also are used to reward exemplary behaviour amongst students, and to support the development of competences for lifelong learning. Additionally, rewarding students using digital badges promotes positive reinforcement of a certain behaviour. When these badges are published in students' social media, it makes their learning more enriching through sharing their achievements with their peers (Lim, Nair, Keppell, Hassan, \& Ayub, 2018). In turn, it increases students' success in learning. 


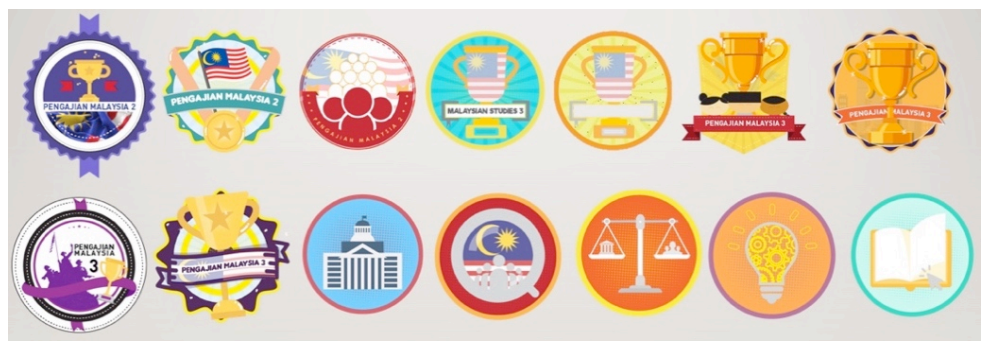

Figure 5. Supporting SRL through the Use of Digital Badges

\section{CONCLUSION}

The study concludes that the improvement in student satisfaction after the implementation of peer learning intervention was due to SRL strategies employed by the students. The significant mediating role played by SRL has drawn attention to the need for educators to provide the support and learning tools necessary to further develop and strengthen students' self-regulation. It is also timely for educators to explore creatively how to enable their students to learn in a self-regulated manner in order to increase their online learning satisfaction.

\section{ACKNOWLEDGEMENT}

The authors would like to thank Centre for Future Learning, Taylor's University and Faculty of Educational Studies, Universiti Putra Malaysia for the support given in carrying out this research.

\section{REFERENCES}

Barnard, L., Lan, W. Y., To, Y. M., Paton, V. O., \& Lai, S. L. (2009). Measuring self-regulation in online and blended learning environments. Internet and Higher Education, 12, 1-6.

Barnard,L., Paton, V. O., \& Lan, W. Y. (2010). Self-regulation across time of first-generation online learners. Research in Learning Technology, 18(1), 61-70.

Boekaerts, M., \& Cascallar, E. (2006). How far have we moved toward the integration of theory and practice in self-regulation? Educational Psychology Review, 18, 199-210. 
Boud, D., Sampson, J., Cohen, R., \& Gaynor, F. (2001). Peer learning in higher education. London: Kogan Page.

Brannagan, K., Dellinger, A., Thomas, J., Mitchell, D., LewisTrabeaux, S., \& Dupre, S. (2013). Impact of peer teaching on nursing students: Perceptions of learning environment, self-efficacy and knowledge. Nurse Education Today, 33(11),1440-1447.

Broadbent,J.,\& Poon,W.L.(2015). Self-regulated learning strategies and academic achievement in online higher education learning environments: A systematic review. Internet and Higher Education, 27, 1-13.

Cho, M.H., \& Shen, D. (2013). Self-regulation in online learning. Distance Education, 34(3), 290-301.

Choi, B. (2016). How people learn in an asynchronous online learning environment: The relationships between graduate students' learning strategies and learning satisfaction. Canadian Journal of Learning and Technology, 42(1). Retrieved from https://www.learntechlib.org/j/CJLT/v/42/n/1/

Cochran, W. G. (1977). Sampling techniques (3rd ed.). New York: Wiley.

Dziuban, C., Hartman, J., Moskal, P. D., Brophy-Ellison, J., \& Shea, P. (2007). Student involvement in online learning. Orlando, FL: Sloan Center for Online Education.

Dziuban, C., Moskal, P., Thompson, J., Kramer L., DeCantis, G., \& Hermsdorfer, A. (2015). Student Satisfaction with Online Learning: Is it a psychological contract? Journal of Asynchronous Learning Network, 19(2). Retrieved from https://files.eric.ed.gov/fulltext/EJ1062943.pdf

Hair, J. F., Jr., Black, W. C., Babin, B. J., \& Anderson, R. E. (2010). Multivariate data analysis (7th ed.). USA: Pearson Prentice Hall.

Holder, B. (2007). An investigation of hope, academics, environment, and motivation as predictors of persistence in higher education online programs. Internet and Higher Education, 10(4), 245-260.

Hussain, R. M. R., \& Al Saaidi, K. K. (2019). Students as designers of E-book for authentic assessment. Malaysian Journal of Learning and Instruction, 16(1), 23-48.

Kelly,R.,\& Schaffhauser,D.(2106). 55 percent of faculty are flipping the classroom. Retrieved from https://campustechnology. com/articles/2016/10/12/55-percent-of-faculty-are-flippingthe-classroom.aspx 
Keppell, M., Suddaby, G., \& Hard, N. (2011). Good practice report: Technology-enhanced learning and teaching. Australian Learning and Teaching Council.

Lee, T.-H., Shen, P.-D., and Tsai, C.-W. (2008). Applying webenabled problem-based learning and self-regulated learning to add value to computing education in Taiwan's vocational schools. Educational Technology and Society, 11, 13-25.

Lehmann, T., Hähnlein, I., \& Ifenthaler, D. (2014). Cognitive, metacognitive and motivational perspectives on preflection in self-regulated online learning. Computers in Human Behavior, $32,313-323$.

Li,K.(2019). MOOC learners' demographics, self-regulated learning strategy, perceived learning and satisfaction: A structural equation modeling approach. Computers \& Education, 132(1), 16-30.

Lim, C. L., Nair, P. K., Keppell, M. J., Hassan, N., \& Ayub, E. (2018). Developing a framework for the university-wide implementation of micro-credentials and digital badges: A case study from a Malaysian private university. IEEE 4th International Conference on Computer and Communications (ICCC), 1715-1719.

Lo, C.C. (2010). How student satisfaction factors affect perceived learning. Journal of the Scholarship of Teaching and Learning, 10(1), 47-54.

Lorenzo, G. (2012). A research review about online learning: Are students satisfied? Why do some succeed and others fail? What contributes to higher retention rates and positive learning outcomes? Internet Learning, 1(1), 46-55.

Lorenzo, G., \& Moore, J. (2002). The Sloan Consortium Report to The Nation: Five Pillars of Quality Online Education. Newburyport, MA, USA: Sloan Consortium.

Martin, J. (2004). Self-regulated learning, social cognitive theory, and agency. Educational Psychologist, 39(2), 135-145.

McFarland, D., \& Hamilton, D. (2005). Factors affecting student performance and satisfaction: Online versus traditional course delivery. Journal of Computer Information Systems 46(2), 2532 .

Morosanova, V. I., \& Fomina, T. G. (2017). Self-regulation as a mediator in the relationship between anxiety and academic examination performance. Procedia-Social and Behavioral Sciences, 23(7), 1066-1070. 
Noel-Levitz, Inc. (2011). National online learners priorities report. Coralville, IA, USA: Author. Retrieved from https://eric. ed.gov/?id=ED537550

O'Connell, A. J. (2016, December 7). What is blended learning in higher ed? Six definitions from thought leaders. Retrieved from http://acrobatiq.com/what-is-blended-learning-inhigher-ed-six-definitions-from-thought-leaders/

Panadero, E., Jonsson, A., \& Botella, J. (2017). Effects of selfassessment on self-regulated learning and self-efficacy: Four meta-analyses. Educational Research Review, 22, 74-98.

Pintrich, P. R. (2000). Multiple goals, multiple pathways: The role of goal orientation in learning and achievement. Journal of Educational Psychology, 92, 544-555.

Preacher, K. J., \& Kelley, K. (2011). Effect size measures for mediation models: Quantitative strategies for communicating indirect effects. Psychological Methods, 16(2), 93-115.

Puzziferro, M. (2008). Online technologies self-efficacy and selfregulated learning as predictors of final grade and satisfaction in college-level online courses. American Journal of Distance Education, 22(2), 72-89.

Rashidi, N., \& Moghadam, M. (2014). The effect of teachers' beliefs and sense of self efficacy on Iranian EFL learners' satisfaction and academic achievement. The Electronic Journal for English as a Second Language, 18(2), 1-23.

Rowe, F. A., \& Rafferty, J. A., (2013). Instructional design interventions for supporting self-regulated learning: Outcomes in postsecondary e-learning environments. MERLOT Journal of Online Learning and Teaching, 9(4), 590-601.

Shen, D., Cho, M., Tsai, C., \& Marra, R. (2013). Unpacking online learning experiences: Online learning self-efficacy and learning satisfaction. Internet and Higher Education, 19, 1017.

Taura, A. A., Abdullah, M. C., Roslan, S., \& Omar, Z. (2014). Selfregulation as a mediator in the relationship between selfefficacy, task value and active procrastination. International Journal of Humanities and Social Science, 4(9), 293-301.

Topping, K. J. (1996). The effectiveness of peer tutoring in further and higher education: A typology and review of the literature. Higher Education, 32(3), 321-345.

Uzezi, J. G., \& Deya, G. D. (2017). Relationship between peer group influence and students' academic achievement in Chemistry at secondary school level. American Journal of Educational Research, 5(4), 350-356. 
Won, I. \& Han, S. S. (2016). The use of a mobile learning management system and academic achievement of online students. Computers and Education, 102, 79-89.

Wong, J., Baars, M., Davis, D., Zee, T. V. D., Houben, G. J., \& Paas, F. (2019). Supporting self-regulated learning in online learning environments and MOOCs: A systematic review. International Journal of Human-Computer Interaction, 35(4-5), 356-373. doi:10.1080/10447318.2018.1543084.

Wu, J. H., Tennyson, R. D., \& Hsia, T. L. (2010). A study of student satisfaction in a blended e-learning system environment. Computers and Education, 55(1), 155- 164.

Zhu, C. (2012). Student satisfaction, performance, and knowledge construction in online collaborative learning. Journal of Educational Technology and Society, 15(1), 127.

Zimmerman, B. J. (2008). Investigating self-regulation and motivation: Historical background, methodological developments, and future prospects. American Educational Research Journal, 45, 166-183.

Zimmerman, B. J. (1989). Models of self-regulated learning and academic achievement. In B.J. Zimmerman \& D. H. Schunk (Eds.): Self-regulated Learning and Academic Achievement: Theory, Research, and Practice (pp. 45-55). New York: Springer-Verlag.

Zimmerman, B. J., \& Schunk, D. H. (2011). Self-regulated learning and performance. In B. J. Zimmerman, \& D. H. Schunk (Eds.), Handbook of self-regulation of learning and performance (pp. 1-12). New York: Routledge. 